\title{
Sebaran Ortofosfat dan Klorofil-a di Perairan Selat Karimata
}

\author{
Gizka Anindya Putri ${ }^{1}$, Muhammad Zainuri ${ }^{1}$, Bayu Priyono ${ }^{2}$ \\ ${ }^{1}$ Program Studi Oseanografi, Fakultas Perikanan dan Ilmu Kelautan, Universitas Diponegoro \\ Kampus Tembalang, Semarang 50275 Telp/Fax. 024-7474698 \\ ${ }^{2}$ Balai Penelitian dan Observasi Kelautan, Jl. Baru Perancak Negara Jembrana Bali \\ email : gizkaanindyaputri@gmail.com
}

\begin{abstract}
Abstrak
Perairan Selat Karimata terletak di antara Pulau Bangka Belitung dan Kalimantan. Perairan ini menghubungkan dua perairan, yakni Laut Jawa dan Laut Cina Selatan. Dinamika kedua perairan tersebut menjadikan Selat Karimata memiliki massa air yang dinamis. Nutrien yang berasal dari Pulau Bangka Belitung dan Kalimantan menyebabkan Selat Karimata memiliki kandungan ortofosfat yang mendukung proses fotosintesa yang dilakukan oleh klorofil-a. Penelitian ini dilakukan untuk mengetahui nilai kandungan serta sebaran antara ortofosfat dan klorofil-a, serta keterkaitan antara ortofosfat dan klorofil-a di perairan Selat Karimata. Pengukuran data lapangan pada penelitian ini dilaksanakan pada 11-14 Juni 2015 di perairan Selat Karimata. Analisa sampel dilakukan di laboratorium Balai Penelitian dan Observasi Laut (BPOL) pada 22-26 Juni 2015. Pengambilan sampel pada penelitian ini dilakukan pada kedalaman 5 meter sebanyak 12 stasiun, dengan mempertimbangkan bahwa setiap stasiun akan merepresentasikan luasan tertentu dari daerah penelitian. Konsentrasi ortofosfat dan klorofil-a adalah dua variabel yang menjadi kajian utama dari beberapa variabel oseanografi yang diukur pada penelitian ini. Hasil penelitian menunjukkan nilai rata-rata ortofosfat sebesar $0,0456 \mathrm{mg} / \mathrm{l}$ dan klorofil-a sebesar $0,2225 \mathrm{mg} / \mathrm{m}^{3}$. Sebaran fosfat dan klorofil-a memiliki pola yang terkonsentrasi disekitar daratan dan kedalaman yang dangkal. Sebaran ortofosfat dan klorofil-a memiliki hubungan yang positif, karena ortofosfat merupakan salah satu nutrien yang dibutuhkan fitoplankton untuk menunjang proses fotosintesa.
\end{abstract}

Kata Kunci: Ortofosfat, Klorofil-a, Selat Karimata

\begin{abstract}
Karimata Strait is located between the islands of Bangka Belitung and Kalimantan. The strait linked two waters, the Java Sea and the South China Sea. The dynamical of these waters made Karimata Strait has a dynamic water mass. The nutrients which derived from Bangka Belitung and Kalimantan islands made Karimata Strait has orthophospate that support photosynthesis process conducted by chlorophyll-a. This research was conducted to determine the distribution and the value of orthophosphate, chlorophyll-a and also their relationships in Karimata Strait. This research was conducted on June 11-14, 2015 in Karimata Strait. Sample analysis was implemented at laboratory of Indonesia's Agency for Marine and Fisheries Research on June 22-26, 2015. Water samples were collected from the surface at depth of 5 meters among 12 stations, by considering the station will represents a specific area of the research area. Ortophosphate and chlorophyll-a were the main studies of variable oceanography which measured. The results showed the average value of ortophosphate is $0,0456 \mathrm{mg} / \mathrm{l}$ and chlorophyll-a is $0,2225 \mathrm{mg} / \mathrm{m}^{3}$. Distribution of ortophosphate and chlorophyll-a were concentrated around the mainland and shallow water. The relationship between ortophosphate and chlorophyll-a were interrelated, because ortophosphate was one of nutrients which required by chlorophyll-a to support photosynthesis.
\end{abstract}

Keywords: Ortophosphate, Chlorophyll-a, Karimata Strait

\section{PENDAHULUAN}

Perairan Selat Karimata menghubungkan dua perairan, yakni Laut Jawa dan Laut Cina
Selatan. Kedua perairan tersebut menjadikan Selat Karimata memiliki massa air yang dinamis. Selat Karimata dipengaruhi oleh daratan di 
sekitarnya, yaitu Pulau Bangka, Pulau Belitung, dan Kalimantan Barat. Hal ini menyebabkan perairan tersebut memiliki kandungan ortofosfat dan mendukung proses fotosintesa yang dilakukan oleh klorofil (Praseno et al., 1984).

Pada sebuah perairan yang berbentuk selat, distribusi massa air di perairan tersebut akan dipengaruhi oleh faktor fisika dan kimia perairan yang dihubungkannya. Persebaran massa air dipengaruhi oleh gelombang, arus, pasang surut, angin, suhu, dan salinitas. Selanjutnya, distribusi massa air akan mempengaruhi faktor kimia seperti $\mathrm{pH}$ dan oksigen terlarut. Persebaran massa air juga berdampak kepada berbagai bahan yang terkandung di dalamnya, salah satunya ortofosfat. Aktivitas manusia di Pulau Bangka Belitung dan Kalimantan menyebabkan adanya masukan nutrien dan klorofil-a ke Selat Karimata. Selain itu, sungai-sungai yang berada di Pulau Bangka Belitung serta Kepulauan Karimata juga ikut menyumbang zat hara di Selat Karimata. Sedimen yang berasal dari muara sungai dan terbawa sampai ke laut akan membawa nutrien yang berasal dari aktivitas manusia.

Penelitian ini dilakukan untuk mengetahui nilai kandungan serta pola sebaran antara ortofosfat dan klorofil-a, serta keterkaitan antara ortofosfat dan klorofil-a di perairan Selat Karimata, Kalimantan Barat - Bangka Belitung.

\section{MATERI DAN METODE}

Materi penelitian yang digunakan berupa data primer dan data sekunder. data primer sebagai data utama, yaitu data ortofosfat dan klorofil-a. Sedangkan data sekunder sebagai data pendukung, yaitu suhu, salinitas, oksigen terlarut (DO), tingkat keasaman (pH), kekeruhan perairan, dan arus. Data primer dan sekunder yang digunakan pada penelitian ini merupakan data yang diperoleh pada 11-14 Juni 2015.

Metode yang digunakan dalam penelitian ini adalah metode kuantitatif, yaitu menggunakan data penelitian berupa angka-angka dan dianalisis menggunakan pendekatan statistik atau model (Sugiyono, 2014). Metode pengambilan sampel air diambil dengan menggunakan botol Niskin, sebanyak $1000 \mathrm{ml}$. untuk analisa klorofila, dan kemudian disaring. Air sampel yang telah disaring selanjutnya dipisahkan sebanyak $500 \mathrm{ml}$ dan dimasukkan dalam botol polietilen untuk analisa ortofosfat. Kedua sampel tersebut di analisa di laboratorium untuk mendapatkan nilai konsentrasinya dengan menggunakan spektrofotometer. Sedangkan parameter kualitas perairan (suhu, salinitas, oksigen terlarut, turbiditas, dan $\mathrm{pH}$ ) dilakukan pengukuran pada perairan dengan menggunakan Conductivity, Depth, and Temperature (CTD).

Penentuan lokasi pengukuran dan pengamatan dilakukan dengan metode purposive sampling. Pengambilan sampel dilakukan pada 12 stasiun pengamatan dengan mempertimbangkan bahwa setiap stasiun akan merepresentasikan luasan tertentu dari areal penelitian. Pengambilan sampel pada titik-titik lokasi yang meliputi wilayah Selat Karimata hingga Selat Galasa.

Analisa sampel klorofil-a dilakukan berdasarkan APHA (2005), yaitu menggunakan metode spektrofotometri dan larutan aseton $90 \%$. Panjang gelombang yang digunakan dalam pengukuran spektrofotometer antara lain $630 \mathrm{~nm}$, $647 \mathrm{~nm}, 664 \mathrm{~nm}$, dan $750 \mathrm{~nm}$. Analisa ortofosfat dilakukan berdasarkan SNI (2005), yaitu menggunakan uji asam askorbat dengan pengukuran konsentrasi menggunakan spektrofotometer. Panjang gelombang yang digunakan yakni $880 \mathrm{~nm}$. Setelah nilai konsentrasi didapat, kemudian divisualisasikan secara 2D dalam bentuk visualisasi spasial dengan menggunakan software ArcGIS 10.0. Visualisasi spasial merupakan hasil dari pengolahan data berupa peta sebaran ortofosfat dan klorofil-a pada perairan Selat Karimata.

\section{HASIL DAN PEMBAHASAN}

Hasil penelitian ini berupa nilai konsentrasi ortofosfat dan nilai konsentrasi klorofil-a. Nilai kandungan ortofosfat rata-rata $0,0456 \mathrm{mg} / \mathrm{l} \pm 0,03$ $\mathrm{mg} / \mathrm{l}$. Nilai kandungan klorofil-a rata-rata 0,2225 $\mathrm{mg} / \mathrm{m} 3 \pm 0,13 \mathrm{mg} / \mathrm{m}^{3}$. Persebaran ortofosfat di perairan Selat Karimata menunjukkan pola konsentrasi bertambah ke arah pantai kepulauan Karimata, serta wilayah pantai Utara dan Barat pulau Belitung (Gambar 1). Kandungan ortofosfat tertinggi pada stasiun 1, sedangkan nilai kandungan ortofosfat terendah pada stasiun 5 (Tabel 1).

Nilai kandungan ortofosfat yang tinggi pada stasiun 1 diduga terkait dengan lokasi penelitian yang terletak diantara banyak pulau, sehingga banyak masukan dari daratan dan vegetasi (mangrove dan lamun). Kadi (2005) menyatakan, bahwa Kepulauan Karimata bagian daratan berhutan lebat dan bagian pantai berhutan mangrove, pada perairan terdapat paparan terumbu dengan substrat $60 \%$ batuan vulkanik bercampur dengan pecahan karang mati, $30 \%$ batu karang dan $10 \%$ pasir. Dinyatakan oleh Edward dan Manik (1987), tingginya kadar ortofosfat disebabkan oleh disosiasi senyawa-senyawa 
ortofosfat menjadi ion ortofosfat yang terdapat di dasar perairan tersebut, juga disebabkan oleh masukan-masukan yang berasal dari sungaisungai, serasah pohon mangrove, letak geografi, dan pengaruh musim. Pada Gambar 1 terlihat adanya variasi yang mencolok di stasiun 3 , 4, dan 5. Hal ini terjadi karena adanya distribusi sedimen oleh arus dan gelombang, sedimen tersebut

Tabel 1. Nilai Konsentrasi Ortofosfat (mg/l) dan Klorofil-a (mg/m³), Selat Karimata, Kalimantan Barat Bangka Belitung

\begin{tabular}{cccc}
\hline Tanggal & Stasiun & Ortofosfat $(\mathrm{mg} / \mathrm{l})$ & Klorofil-a $\left(\mathrm{mg} / \mathrm{m}^{3}\right)$ \\
\hline 11 Juni 2015 & 7 & 0,057 & 0,40 \\
11 Juni 2015 & 8 & 0,007 & 0,05 \\
11 Juni 2015 & 9 & 0,007 & 0,05 \\
12 Juni 2015 & 10 & 0,057 & 0,42 \\
12 Juni 2015 & 5 & 0,002 & 0,21 \\
13 Juni 2015 & 1 & 0,081 & 0,15 \\
13 Juni 2015 & 2 & 0,072 & 0,21 \\
13 Juni 2015 & 3 & 0,007 & 0,22 \\
13 Juni 2015 & 4 & 0,052 & 0,15 \\
13 Juni 2015 & 6 & 0,067 & 0,40 \\
14 Juni 2015 & 11 & 0,062 & 0,15 \\
14 Juni 2015 & 12 & 0,076 & 0,26 \\
\hline
\end{tabular}
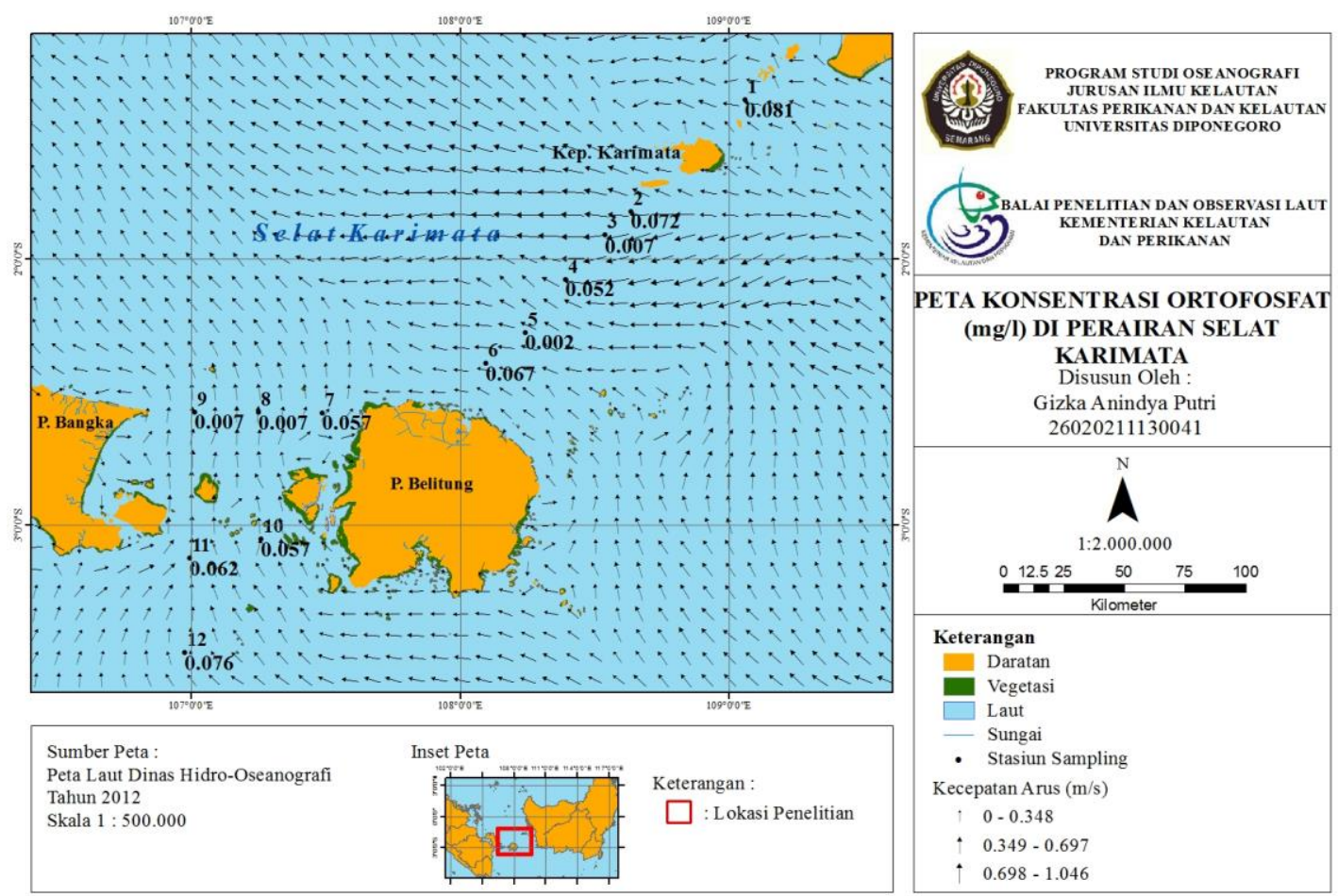

Gambar 1. Peta Sebaran Konsentrasi Ortofosfat (mg/l) di Selat Karimata, Kalimantan Barat - Bangka Belitung. 
mengandung zat hara dan bahan organik (Makatita, 2014). Zat hara dan bahan organik dalam sedimen akan terangkat ke lapisan permukaan saat terjadi pengadukan perairan. Oleh karena itu, kandungan ortofosfat pada stasiun 4 lebih tinggi karena pengadukan air di daerah yang lebih dangkal dibanding stasiun 3 dan 5. Hal ini dibuktikan dengan data kedalaman saat di lapangan, bahwa stasiun 3, 4, dan 5 masingmasing memiliki kedalaman 41m, 40m, dan 41m.

Persebaran klorofil-a di perairan Selat Karimata mempunyai pola yang terkonsentrasi di sekitar Pulau Belitung (Gambar 2). Klorofil tertinggi berada pada stasiun 10 dan nilai terendah pada stasiun 8 dan 9. Berdasarkan arah arus selama pengambilan sampel, pada wilayah titik sampling 7 sampai 12 arus bergerak dengan kecepatan relatif cepat pada tengah selat. Hal ini meyebabkan persebaran klorofil yang tidak merata, khususnya pada titik 8 dan 9. Garis pantai Pulau Bangka yang berbentuk cekung mengakibatkan akumulasi bahan organik yang terbawa massa air masuk dan terperangkap ke dalam cekungan, sehingga hanya sedikit zat hara yang terbawa arus ke titik 8 dan 9. Nilai klorofil-a yang tinggi pada titik 10 disebabkan oleh banyaknya vegetasi (mangrove dan lamun) di sekitar titik tersebut. Titik 6 dan 7 juga memiliki nilai klorofil yang lebih tinggi di banding stasiun lainnya karena stasiun tersebut berada dekat dengan daratan. Wirasatriya (2011) menyatakan, adanya gradasi nilai konsentrasi klorofil-a yang tinggi di daerah pantai, terutama muara sungai dan semakin rendah menuju ke arah laut lepas. Dengan demikian, sebaran klorofil-a yang terbentuk di lokasi penelitian dipengaruhi berbagai faktor fisika, kimia, dan biologi di wilayah tersebut.

Fosfat dan klorofil-a memiliki keterkaitan satu sama lain, seperti yang terlihat pada Gambar 3 , khususnya stasiun 8 dan 9 dimana terlihat nilai ortofosfat yang rendah juga mengakibatkan nilai klorofil-a yang rendah. Hal ini dijelaskan oleh Zainuri (2010), yakni ketersediaan unsur nutrisi yang terbatas akan menjadi faktor pembatas bagi biota fitoplankton, selaku produser primer, untuk melakukan proses fotosintesa. Pada stasiun 6,7 , dan 10 diduga disebabkan oleh adanya suplai nutrien dari daratan, sehingga banyak fitoplankton yang memanfaatkan ortofosfat untuk pertumbuhan melalui proses fotosintesa. Seperti dijelaskan oleh Santoso (2007), organisme utama yang memerlukan keberadaan unsur ortofosfat di perairan adalah fitoplankton untuk digunakan dalam proses fotosintesa. Proses fotosintesa yang dilakukan oleh fitoplankton memberikan peluang dihasilkannya unsur-unsur mikro nutrien (astaxantin dan $\beta$-karoten) yang merupakan deposan dan bahan lanjut dari terbentuknya klorofil (Zainuri, 2010). Stasiun 12 memiliki nilai kandungan ortofosfat dan klorofil-a tinggi, walaupun stasiun tersebut berada jauh dari garis pantai. Hal ini disebabkan adanya pengadukan massa air yang mengakibatkan terangkatnya kandungan zat hara yang tinggi dari dasar perairan ke lapisan permukaan, didukung pula dengan nilai kedalaman yang rendah, yakni $18,4 \mathrm{~m}$. Secara vertikal distribusi klorofil-a tidak selalu maksimum pada kolom air atau pun pada permukaan perairan, namun terkadang lebih banyak di dasar perairan pada perairan dangkal (Syah, 2009). Stasiun 1, 2, 3, 4, 5, dan 11 tidak memiliki keterkaitan antara ortofosfat dan klorofil-a. Hal ini dapat disebabkan karena pengaruh letak perairan Selat Karimata. Perairan laut tropis pada umumnya memiliki kandungan klorofil-a rendah karena keterbatasan nutrien dan kuatnya stratifikasi kolom air. Tubawalony (2007) menyatakan bahwa stratifikasi kolom air disebabkan oleh pemanasan permukaan perairan yang hampir sepanjang tahun.Variasi sebaran klorofil-a secara musiman maupun spasial, dibeberapa bagian perairan dijumpai kosentrasinya yang cukup tinggi. Hal ini disebabkan karena adanya pengkayaan nutrien pada lapisan permukaan perairan melalui berbagai proses dinamika massa air, diantaranya upwelling, percampuran vertikal massa air serta pola pergerakkan massa air, yang membawa massa air kaya nutrien dari perairan sekitarnya. Proses pengambilan sampel yang dilakukan pada kedalaman 5 meter juga dapat mempengaruhi konsentrasi klorofil-a. Menurut Tubawalony (2007), sebaran konsentrasi klorofil bagian atas lapisan tercampur sangat sedikit dan konsentrasinya mulai meningkat menuju bagian bawah dari lapisan tercampur dan menurun secara drastis pada lapisan termoklin, hingga tidak ada lagi klorofil-a pada lapisan di bawah termoklin.

Pada penelitian ini digunakan data pendukung berupa suhu, salinitas, oksigen terlarut, $\mathrm{pH}$, dan turbiditas. Hasil pengamatan terhadap nilai suhu menunjukkan nilai kisaran $29,3788^{\circ} \mathrm{C}-30,0152^{\circ} \mathrm{C}$ dengan nilai rata-rata $29,6126^{\circ} \mathrm{C} \pm 0,1799^{\circ} \mathrm{C}$. Nilai suhu tertinggi ditunjukkan pada stasiun 9 dengan nilai $30,0152^{\circ} \mathrm{C}$ dan nilai suhu terendah $29,3788^{\circ} \mathrm{C}$ pada stasiun 6 (Tabel 2). Hasil pengamatan 
terhadap nilai salinitas menunjukkan nilai kisaran 31,3187 PSU - 32,9968 PSU dengan nilai ratarata 32,4812 PSU $\pm 0,5151$ PSU. Nilai salinitas tertinggi ditunjukkan pada stasiun 9 dengan nilai 32,9968 PSU dan nilai salinitas terendah 31,3187 PSU pada stasiun 1 (Tabel 2). Hasil pengamatan terhadap nilai oksigen terlarut menunjukkan nilai kisaran 4,0752 $\mathrm{ml} / \mathrm{l}$ - 4,1969 $\mathrm{ml} / \mathrm{l}$ dengan nilai rata-rata $4,1249 \mathrm{ml} / 1 \pm 0,0337 \mathrm{ml} / \mathrm{l}$. Nilai oksigen terlarut tertinggi ditunjukkan pada stasiun 11 dengan nilai $4,1969 \mathrm{ml} / \mathrm{l}$ dan nilai oksigen terlarut terendah 4,0752 $\mathrm{ml} / 1$ pada stasiun 8 (Tabel 2).
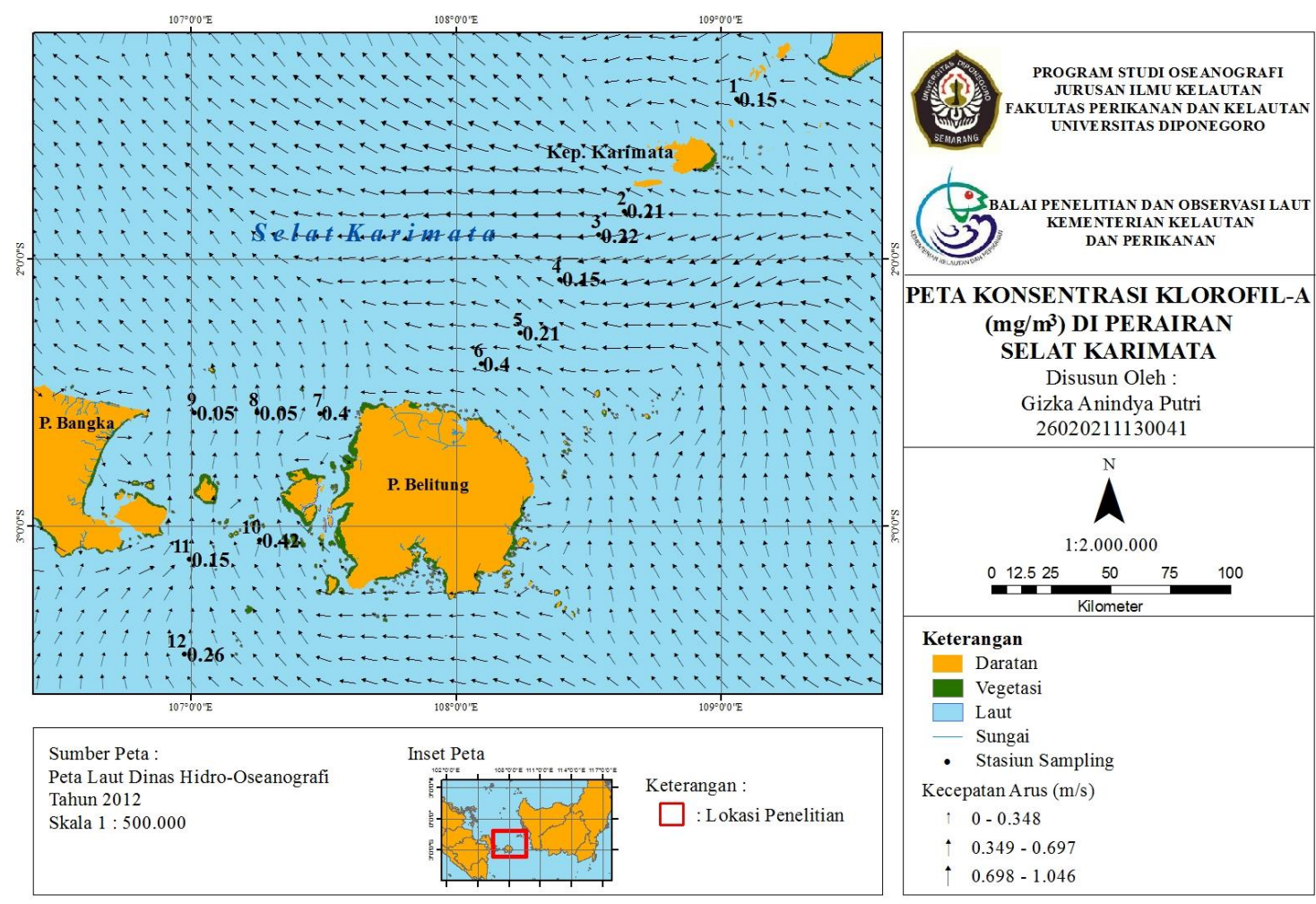

Gambar 2. Peta Sebaran Konsentrasi Klorofil-a $\left(\mathrm{mg} / \mathrm{m}^{3}\right)$ di Selat Karimata, Kalimantan Barat - Bangka Belitung.

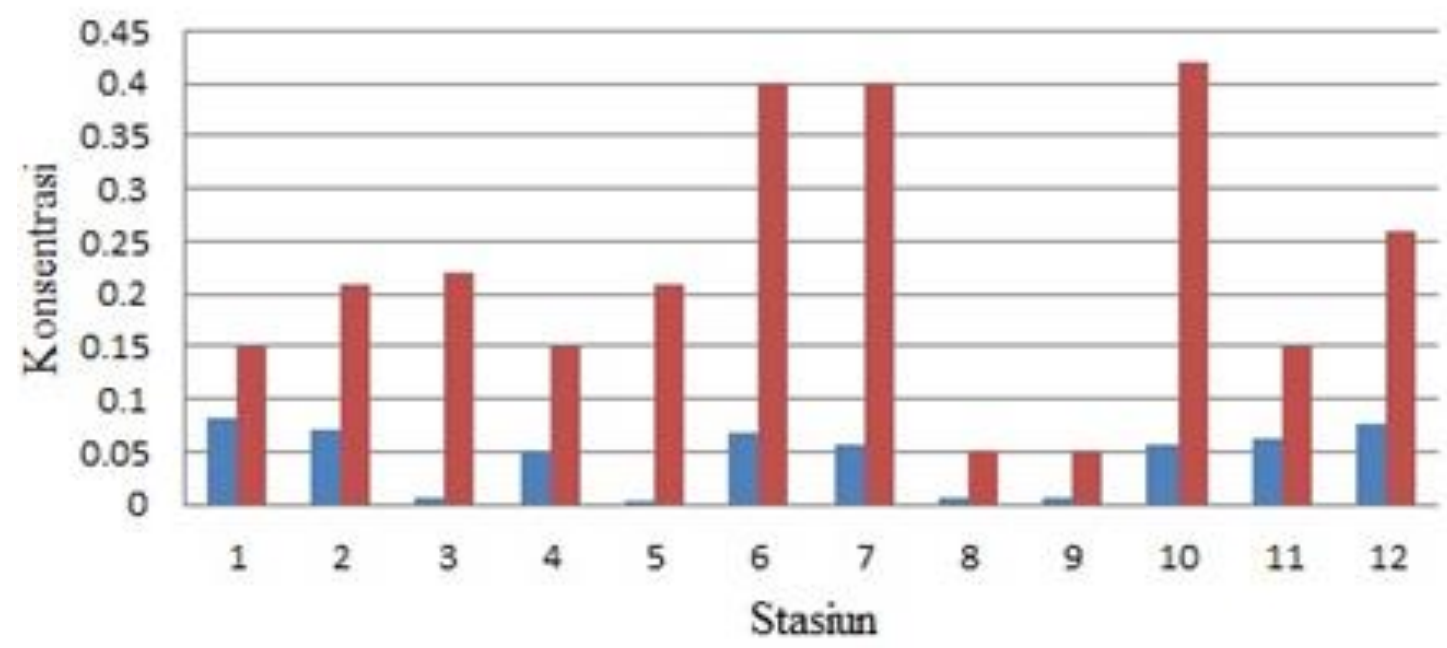

Ortofosfat Elorofil-a

Gambar 3. Diagram Konsentrasi Ortofosfat dan Klorofil-a di Selat Karimata, Kalimantan Barat - Bangka Belitung. 
Tabel 2. Data Parameter Kualitas Air di Perairan Selat Karimata, Kalimantan Barat - Bangka Belitung

\begin{tabular}{|c|c|c|c|c|c|c|}
\hline Stasiun & Tanggal & $\begin{array}{l}\text { Suhu } \\
\left({ }^{\circ} \mathrm{C}\right)\end{array}$ & $\begin{array}{l}\text { Salinitas } \\
\text { (PSU) }\end{array}$ & $\begin{array}{l}\mathrm{DO} \\
(\mathrm{ml} / \mathrm{l})\end{array}$ & $\mathrm{pH}$ & $\begin{array}{c}\text { Turbiditas } \\
\text { (NTU) }\end{array}$ \\
\hline 1 & 13 Juni 2015 & 29,8897 & 31,3187 & 4,1485 & 8,578 & 1,791 \\
\hline 2 & 13 Juni 2015 & 29,5785 & 31,8981 & 4,1022 & 8,535 & 2,004 \\
\hline 3 & 13 Juni 2015 & 29,5188 & 32,0856 & 4,0957 & 8,544 & 1,797 \\
\hline 4 & 13 Juni 2015 & 29,5092 & 32,2731 & 4,1405 & 8,575 & 1,840 \\
\hline 5 & 12 Juni 2015 & 29,5023 & 32,4568 & 4,1261 & 8,575 & 1,842 \\
\hline 6 & 13 Juni 2015 & 29,3788 & 32,4496 & 4,1178 & 8,572 & 1,827 \\
\hline 7 & 11 Juni 2015 & 29,6408 & 32,9364 & 4,1551 & 8.575 & 1,809 \\
\hline 8 & 11 Juni 2015 & 29,6956 & 32,9743 & 4,0752 & 8,583 & 1,876 \\
\hline 9 & 11 Juni 2015 & 30,0152 & 32,9968 & 4,1427 & 8,603 & 1,809 \\
\hline 10 & 12 Juni 2015 & 29,5662 & 32,8023 & 4,1032 & 8,579 & 1,956 \\
\hline 11 & 14 Juni 2015 & 29,5802 & 32,8743 & 4,1969 & 8,581 & 1,809 \\
\hline \multirow[t]{3}{*}{12} & 14 Juni 2015 & 29,4763 & 32,7079 & 4,0946 & 8,567 & 1,962 \\
\hline & $\begin{array}{c}\text { Rata-rata } \\
(\bar{x})\end{array}$ & 29,6126 & 32,4812 & 4,1249 & 8,5722 & 1,86 \\
\hline & $\begin{array}{c}\text { Simpangan } \\
\text { Baku (s) }\end{array}$ & 0,18 & 0,52 & 0,03 & 0,02 & 0,07 \\
\hline
\end{tabular}

Pengamatan terhadap nilai $\mathrm{pH}$ menunjukkan nilai kisaran 8,535 - 8,603 dengan nilai rata-rata $8,5722 \pm 0,0177$. Nilai $\mathrm{pH}$ tertinggi ditunjukkan pada stasiun 9 dengan nilai 8,603 dan nilai $\mathrm{pH}$ terendah 8,535 pada stasiun 2 (Tabel 6). Hasil pengamatan terhadap nilai turbiditas menunjukkan nilai kisaran 1,791 NTU - 2,004 NTU dengan nilai rata-rata $1,8600 \mathrm{NTU} \pm 0,0732$ NTU. Nilai turbiditas tertinggi ditunjukkan pada stasiun 2 dengan nilai 2,004 NTU dan nilai turbiditas terendah 1,791 NTU pada stasiun 1 (Tabel 2).

Air laut dengan tingkat kekeruhan rendah akan meneruskan spektrum cahaya hingga menembus sampai lapisan yang dalam. Pada saat pengambilan sampel, rata-rata nilai turbiditas di perairan adalah 1,86 NTU. Hal ini menandakan bahwa perairan Selat Karimata memiliki perairan yang jenih serta mendukung untuk proses fotosintesa karena sinar matahari dapat masuk ke dalam perairan dengan intensitas yang tinggi. Dijelaskan oleh Sutomo dan Hutagalung (1993), jika suatu perairan memiliki nilai turbiditas $>30$ NTU, akan menghambat pertumbuhan fitoplankton dan kehidupan biota di perairan tersebut. Fitra et al., (2013) menjelaskan, bahwa konsentrasi klorofil-a dipengaruhi oleh beberapa faktor pertumbuhan fitoplankton, salah satunya adalah intensitas sinar matahari. Oksigen terlarut merupakan salah satu faktor dibutuhkan oleh bakteri untuk menguraikan zat organik menjadi zat anorganik (Simanjuntak, 2009). Berdasarkan Nilai Ambang Batas (NAB) Baku Mutu Kementerian Lingkungan Hidup untuk kadar oksigen terlarut dalam suatu perairan yaitu $>5$ mg/l (KMNLH, 2004), maka perairan Selat Karimata merupakan perairan yang kurang baik untuk pertumbuhan organisme akuatik, karena kadar oksigen terlarut hanya 4,7 - 4,84 mg/l. Hal ini menandakan bahwa proses fotosintesa tidak berlangsung maksimal, sehingga oksigen sebagai produk fotosintesa bernilai rendah. $\mathrm{pH}$ perairan Selat Karimata berkisar 8,535 - 8,603, nilai tersebut baik untuk kehidupan biota laut yang membutuhkan $\mathrm{pH}$ berkisar antara 5 - 9 (Simanjuntak, 2009).

Berdasarkan pengukuran suhu dan salinitas di lokasi penelitian, kedua parameter tersebut dalam batas normal yang dapat memenuhi produktivitas perairan dan kehidupan biota laut. Selat Karimata yang dangkal menyebabkan pengaruh angin (dragforce) masih dominan 
mengakibatkan terjadinya pengadukan massa air dengan mudah. Distribusi suhu dan salinitas berdasarkan data lapangan, di peroleh nilai suhu dan salinitas yang relatif homogen terhadap kedalaman. Suhu dan salinitas yang homogen ini menjadi indikasi adanya proses pengadukan vertikal yang kuat (well mixed). Dengan demikian sebaran ortofosfat dan klorofil-a di perairan Selat Karimata sangat dipengaruhi oleh faktor oseanografi biologi, kimia, dan fisika.

\section{SIMPULAN}

Berdasarkan hasil yang diperoleh dalam penelitian ini, maka diperoleh kesimpulan sebagai berikut :

1. Konsentrasi ortofosfat di perairan Selat Karimata menunjukkan nilai rata-rata 0,0456 $\pm 0,03 \mathrm{mg} / \mathrm{l}$. Sebaran fosfat menunjukkan pola konsentrasi semakin bertambah ke arah pantai.

2. Konsentrasi klorofil-a di perairan Selat Karimata menunjukkan nilai rata-rata 0,2225 $\pm 0,13 \mathrm{mg} / \mathrm{m}^{3}$. Sebaran klorofil-a memiliki pola yang terkonsentrasi di sekitar Pulau Belitung.

3. Sebaran ortofosfat dan klorofil-a memiliki hubungan yang positif, dengan kecenderungan konsentrasi semakin bertambah ke arah pantai. Hal ini dikarenakan ortofosfat merupakan salah satu nutrien yang dibutuhkan klorofil-a untuk menunjang proses fotosintesa.

\section{UCAPAN TERIMA KASIH}

Penulis mengucapakan terimakasih kepada semua pihak yang telah membantu terlaksananya penelitian ini, terutama pada program SITE (The South China Sea-Indonesia Seas Transport/Exchange) Cruise, yaitu program kerjasama penelitian antara Kementerian Kelautan dan Perikanan dan First Institute of Oceanography - China. Artikel ini adalah bagian dari skripsi penulis pertama yang dibimbing oleh penulis kedua dan ketiga. Tidak lupa diucapkan terimakasih kepada Teguh Agustiadi, S.T (BPOL) selaku Chief Party, Dr. R. Dwi Susanto (University of Maryland) selaku Chief Scientist, dan Fan Bin (FIO-SOA).

\section{DAFTAR PUSTAKA}

APHA (American Public Health Association). 2005. Inorganic Non Metallic Constituents, in: Standard Methods for the Examination of Water and Wastewater. 21sted., American
Public Health Association, Washington D.C., $1368 \mathrm{p}$.

Badan Standarisasi Nasional. 2005. Cara Uji Kadar Fosfat Secara Asam Askorbat dengan Spektrofotometer. SNI 06-6989.31-2005, 10 hlm.

Edward, dan J.M. Manik. 1987. Kandungan Zat Hara Fosfat di Teluk Ambon Pada Musim Timur dan Musim Barat. Balitbang Sumber Daya Laut, Puslitbang Oseanologi, LIPI : 112 $-116$.

Fitra, F., I. J. Zakaria dan Syamsuardi. 2013. Produktivitas Primer Fitoplankton di Teluk Bungus. Jurnal Biologika., 2 : 59-66.

Kadi, A. 2005. Makro Algae di Perairan Kepulauan Bangka, Belitung dan Karimata. Jurnal Ilmu Kelautan., 10 : 98-105.

Makatita, J.R., A.B. Susanto dan J.C. Mangimbulude. 2014. Kajian Zat Hara Fosfat dan Nitrat Pada Air dan Sedimen Padang Lamun Pulau Tujuh Seram Utara Barat Maluku Tengah. Jurnal Biologi., 3 : 55-66.

Praseno, D.P., W. Kastoro dan M.K. Moosa. 1984. Evaluasi Kondisi Perairan Selat Bangka 1977 - 1978, LIPI : 7-12.

Santoso, A.D. 2007. Kandungan Zat Hara Fosfat Pada Musim Barat dan Musim Timur di Teluk Hurun Lampung. Jurnal Teknik Lingkungan., 8 : 207-210.

Simanjuntak, M. 2009. Hubungan Faktor Kimia, Fisika Terhadap distribusi Plankton di Perairan Belitung Timur, Bangka Belitung. Jurnal Perikanan., 11 : 31-45.

Sugiyono. 2009. Metode Penelitian Kuantitatif, Kualitatif, dan R\&D. Alfabeta, Bandung, 334 hlm.

Sutomo dan H.P. Hutagalung. 1993. Pengamatan Kandungan Klorofil-a di Perairan Muara Sunter, Teluk Jakarta. Dalam: Seminar Pemantauan Pencemaran Laut Tanggal 07-09 Februari 1994-LIPI : 137-142. 
Syah, A.F. 2009. Distribusi Vertikal Klorofil-a di Perairan Laut Banda Berdasarkan Neural Network. [Tesis]. Sekolah Pascasarjana, Institut Pertanian Bogor, Bogor, 78 hlm.

Tubalawony, S. 2007. Kajian klorofil-a dan Nutrisi serta Interelasinya dengan Dinamika Massa Air di Perairan Barat Sumatera dan Selatan Jawa-Sumbawa. [Disertasi]. Sekolah Pascasarjana, Institut Pertanian Bogor, Bogor, 161 hlm.

Wirasatriya, A. 2011. Pola Distribusi Klorofil-a dan Total Suspended Solid (TSS) di Teluk
Toli Toli, Sulawesi. Buletin Oseanografi Marina., 1 : 137-140.

Zainuri, M. 2010. Kontribusi Sumberdaya Fitoplankton Terhadap Produktivitas dan Keseimbangan Ekosistem dalam Pengelolaan Wilayah Pesisir. Makalah Pengukuhan Guru Besar, Semarang, 79 hlm. 